\title{
Motivators and Barriers of Chatbot Usage in Recruiting: An Empirical Study on the Job Candidates Perspective in Germany
}

Linda Schildknecht, Judith Eißer, Stephan Böhm

RheinMain University of Applied Sciences

Department of Media Management

Unter den Eichen Campus

Wiesbaden, Germany

ABSTRACT: Human resource management and recruiting in particular are subject to constant change - not least due to everincreasing digitalization. One way to improve efficiency in digital recruiting is to automate process steps using innovative technologies. In this context, chatbots are innovative conversational systems that offer such a potential. When applied to the field of recruiting, a chatbot can establish a new channel for the communication between a company and potential applicants. This paper investigates motivators and barriers of recruiting chatbot usage as well as the candidates' expectations and preferences on the chatbot design. Moreover, factors influencing the perception of recruiting chatbots derived from the theory of social presence were investigated. The empirical study was carried out in the form of a quantitative online questionnaire within a sample of 213 respondents in Germany. As a result, the study reveals a general interest in the usage of recruiting chatbots as well as important motivators, barriers, and design preferences from the candidate perspective.

Keywords: Chatbots, Recruiting, Recruiting Chatbots, User Preferences, Empirical Study

Received: 10 July 2018, Revised 19 August 2018, Accepted 9 September 2019

DOI: $10.6025 /$ jet/2018/9/4/109-123

(C) 2018 DLINE. All Rights Reserved

\section{Introduction}

Factors such as demographic change and the resulting shortage of skilled workers has led the German recruiting industry to a socalled "war of talents", i.e., a high level of competition for qualified staff (Bollessen 2014). At the same time, however, recruiters are required to keep costs of hiring an employee as low as possible (Ritter 2010). Another important development is the increasing importance of e-recruiting. The term of e-recruiting refers to the use of digital technologies and systems to support the recruitment 
process from the posting of vacant positions to the receipt and processing of applications (Knight 2010). In recent years, Web 2.0 technologies such as social or mobile media have already been successfully applied in the field of e-recruiting. Recruitment channels such as the company website, Internet job portals or career networks offer a more flexible and cost-effective solution for personnel recruitment than traditional print advertising, while at the same time reaching a wider range of potential applicants (Ritter 2010; Chris 2018a). It is expected that based on technologies such as artificial intelligence (AI) and Big Data, a new trend will emerge that could fundamentally change recruiting processes and also enable cost savings: chatbots (JobStairs 2017).

Chatbots, i.e. dialogue or conversational systems with which humans can interact in natural language, are not a new phenomenon. As early as in the 1960s, Joseph Weizenbaum created ELIZA, the first chatbot that enabled human-machine interaction in natural language (Storp 2002). However, the topic has only recently been attracting increased attention. Latest advances in information systems and AI have enabled new fields of application and use cases for chatbots, making them more attractive for companies (Marr 2018). In addition to this general increase of attention for chatbots, more and more HR managers are getting aware and discussing opportunities concerning the use of chatbots in the specific area of recruiting (JobStairs 2017). A chatbot solution could be used to make recruitment processes more efficient by transferring time-consuming repetitive and standardized tasks with a high automation potential from HR personnel to a recruiting chatbot. For example, a chatbot could be used for answering general questions on the employer, vacancies, job requirements, and application procedures. Depending on the technical performance and the integration into existing HR information systems, more advanced functions can also be taken over. This includes information about the application status, simple standardized interviews, and structured queries of applicant information or inquiries when applicants' documents or information are missing.

However, for chatbots to successfully take on tasks, potential candidates must also want to interact with them. Currently, there is a research gap on candidates' preferences and expectations on recruiting chatbots. However, it is the applicant perspective that might be particularly interesting for companies that work with a recruiting chatbot or want to use one in the future. If the perspective of the candidates is not taken into account in the development of chatbots, this can lead to the rejection of the systems and ultimately to the commercial failure of corresponding projects (Schönecker 1982; Schnell 2007).

Against this background, this paper examines the applicants' perspective and looks at their requirements and preferences on recruiting bots. The study's aim is to use these findings to derive recommendations for the design of chatbots in practice. Based on this main objective, the following research questions will be investigated (among potential candidates in Germany):

- Is there a general interest or willingness in using recruiting chatbots?

- What motivators and barriers do potential applicants see in the use of recruiting chatbots?

- For which functions and contents would potential applicants like to use a recruiting chatbot?

- How does design and social presence influence the perception of recruiting chatbots?

This paper is structured as follows: Chapter 2 presents some selected conceptual backgrounds as the basis of the recruiting study. This is followed by a presentation of the empirical study approach in Chapter 3 and its results in Chapter 4 . The discussion of management implications and limitations of the study will then be discussed in Chapter 5 before this article concludes with a summary in Chapter 6.

\section{Conceptual Background of Recruiting Chatbots}

\subsection{Chatbot Support in the Recruiting Process}

The artificial term chatbot is made up of the two English words "chat" and "bot", which is the short form for "robot" (Gennermann/ Hack 2011). Accordingly, such systems provide an automated conversation interface to support dialogs with human users. There are similar terms used for chatbots such as chatter bot, virtual agent, conversational agent, machine conversation system and dialogue system (Shawar/Atwell 2007; van Euwen 2017). This paper follows the understanding of Shawar and Atwell, who describe chatbots as computer programs with which the user can interact in natural language (Shawar/Atwell 2007). Natural language communication is the key aspect that differentiates chatbots from other computer programs. This form of interaction creates an intuitive interface that represents "an innovative step in the development of human-computer interaction" (Ferdinand/ Jetzke 2017). The user can communicate with the system in a way that feels natural. Chatbots are either rule-based or based on AI: Rule-based chatbots follow a strict, predefined structure (so-called pattern matching), in which input is matched against a

$110 \quad$ Journal of E-Technology Volume 9 Number 4 November 2018 
cally replicate human problem-solving behaviour by independently collecting and processing data, recognizing rules and learning to solve problems more efficiently (Lämmel/Cleve 2012; Manhart 2018). In addition, further implementation variants of chatbots can be distinguished. For example, chatbots can be text- or voice-oriented. They can be implemented either in messenger systems, on websites or smart speakers (Zadrozny et al. 2000; Desaulniers 2016;Schlicht 2016).

Different types of chatbots can also be defined with regard to the fields of application. There is a multitude of scenarios in which chatbots can be used or are already used today. A prevalent field of application is customer service, as this is a dialogueintensive interface between customers and companies (Stucki et al. 2018). This article focuses on the application of chatbots within the recruiting process. The recruiting process consists of the following steps (1) Personnel requisition, (2) Creation and posting of the job advertisement, (3) applicant consultation and reception of application, (4) Screening and evaluation of application documents, (5) planning and conducting interviews/selecting applicants, and (6) Hiring decision and on boarding. The term recruiting chatbots is used in the following for the use of chatbots to support one or more of these phases of the recruiting process. In principle, recruiting chatbots can be used by companies internally or externally. An internal application scenario, for example, would be to support a line manager in formulating a job advertisement. In external use, for example, a chatbot may concern questions from potential applicants about the requirements formulated in a job advertisement. This article focuses on the external use and thus the support of the dialogue between employer and applicant.

In Germany, there are few findings on the awareness and use of recruiting chatbots so far.

The following section examines the status quo of recruiting chatbots on the German market. First insights revealed by a recent study focussed on digital career consultants, a form of chatbots which answers general questions about vacancies, career opportunities and the company itself. According to CHRIS (2018), half of the respondents of the study stated that they would like to use such systems in the future. The willingness to use them, however, varies across the different age groups. One third of the respondents in the baby boomer generation stated they would be willing to use such systems, while this figure rose to about 50 percent of Generation X and 60 percent of Generation Y respondents. Digital natives thus are characterized by a greater degree of open-mindedness towards digital career advisors than digital immigrants. However, more than half of the respondents rejected the automated pre-selection of applications (CHRIS 2018; see also JobStairs 2016). On the part of the companies, only 2.8 percent of the top 1,000 companies surveyed in Germany are using a recruiting bot in 2018. Even though the majority of companies currently do not use job bots yet, six out of ten companies assume that chatbots will be used more and more frequently in recruitment (CHRIS 2017; CHRIS 2018).

\subsection{Related Work on Motivators and Barriers or Chatbot Usage}

The development and distribution of recruiting chatbots is still at an early stage. Further dissemination will depend on the extent to which motivators can stimulate use and barriers to use can be overcome. There are advantages of recruiting chatbots such as the saving of working time and labor from the recruiters' perspective. Similar advantages can also be found from the applicant's point of view (Eisenkrämer 2017): The central motivators here are time savings as well as time flexibility. In contrast to real recruiters, who are bound to office hours, a recruiting chatbot is available any time and can process a large number of inquiries from applicants at the same time (Queb 2017). According to a recent applicant study in Germany, the most important requirement in the application process is to get a quick response (Slaghuis 2017). Due to real-time communication, applicants receive answers to enquiries without a delay and in a matter of seconds. Assuming there is an Internet connection, the recruiting chatbot also provides ubiquitous access and can be approached from any location and via any device (Kreuzmann 2018).

However, there are other advantages beyond improved availability and reach ability. In contrast to humans, a chatbot decides based on a predefined or programmed logic, which treats all candidates in the same way and is initially free of prejudices or antipathies. It can act without discrimination as opposed to human staff who, often subconsciously, may make personnel decisions based on attitudes or stereotypes (Kramer 2018). In the past, studies have already shown that people with a foreignsounding name, or women in comparison to men, have a demonstrably lower chance of being invited to an interview (LüpkeNarberhaus 2014; WZB 2017). Greater equality of opportunity can be achieved by the unprejudiced handling of the users via a recruiting chatbot. This presupposes, however, that no discriminatory rules are applied and that training data is available for AIchatbots that are not biased by discriminatory behaviour. Another advantage of chatbot usage is an assumed lower hurdle for making the contact compared to starting a dialogue with a real recruiter. This can motivate the applicant to ask questions more freely. For example, evaluations of various conversations with the German recruiting chatbot "Hub Bot" showed that about 30 percent of the applicants asked questions about salary and bonuses right at the beginning of the interview. In a personal 
interaction with a human recruiter, this type of question is typically asked much later, if at all (Kreuzmann 2018). Another advantage is the simplicity and ease of use. The users can interact with the system in a very intuitive and natural form. They just type in their question as text in a chat window and do not have to learn to operate a user interface, i.e., the navigation structure of a web page (Asher 2017).

In addition to these potential motivators, there are some barriers that can make the use of recruiting chatbots more difficult. Here, the issue of high susceptibility to errors due to free text and speech input is a problem (Jung/Niemayer 2017). For example, the error rate of the chatbots integrated in Facebook Messenger in 2017 was noticeable: these systems failed in about 70 percent of the requests (Sun 2017). On the one hand, this is because the bots are not technically mature yet. On the other hand, natural language itself harbours risks that make successful communication difficult. Ambiguities of terms, irony, colloquial language or spelling mistakes during interaction can lead to the bot not being able to accurately interpret the questions (Hensel/Litzel 2018). To date, many bots do not have a broad enough knowledge base to understand complex relationships and contexts. This could also be an explanation why some studies (JobStairs 2016) reveal that users believe chatbots to be less competent than human beings. Susceptibilities to errors and a lack of understanding can lead to a communication disturbance or even interruption, which means the user has spent time without receiving any assistance in terms of his request. This can in turn result in imprinting a negative attitude towards chatbots, which is an obstacle to future use and acceptance. Another potential usage barrier refers to reservations due to privacy concerns and data protection. According to a study on these topics (Grieger\& Cie. Marktforschung 2016), Germans demand a high level of data security: 83 percent of those surveyed stated that data protection is very important and 85 percent pay close attention to what data they disclose about themselves on the Internet. With chatbot interactions, it is often not clear to the user to what extent the information is stored and used. This could be a major hurdle, especially during the application process, when some applicants disclose sensitive personal data. A potential usage barrier to AI-based chatbots are low user numbers: To provide a high interaction quality and enable continuous improvement, these chatbots need a large amount of data. An insufficient amount of training data results in a low performance, which in turn could deter further users and make improvement through learning impossible.

\subsection{Design Options and Impact of Social Presence}

The design of chatbots includes various aspects, from the selection of tasks and content to the technical implementation and the design of the user interface. A major difference to the design of traditional user interfaces of information systems is that decisions on the form or presentation and use of language are more important. For example, the chatbot can be given its own personality by an avatar or presented impersonally in the form of a chat window. Conversations could be supported by text only or by using additional graphical elements such as emojis. Candidates may be approached by the chatbot in a personalized way (e.g. addressing them by their first name) or impersonally (this may require registration of the user). The tonality of the language can be emotional or factual. Depending on the language, other decisions concerning the language style have to be considered. In the German language, for example, there is a distinction between a formal (Sie) and informal (Du) pronominal address. This decision can have an impact on how personally the communication is perceived or whether a communication relationship is perceived as distant or imminent.

Decisions on the chatbot design should be based on the company's employer branding and recruiting strategy. The design needs to be user oriented and thus aligned with the specific information and support needs of the target group. For the effective use of a chatbot, it must be equipped with relevant information desired by the applicant. Seven out of ten potential applicants inform themselves about a company in detail before applying (Market Agent 2015). In addition to information channels such as employer rating portals, social media and job portals, recruiting chatbots are an opportunity to obtain information about the company. Employer information perceived as important is, for example, the remuneration, type of work, location, career opportunities, corporate vision, corporate image, organisation of working hours, special benefits, working environment and family friendliness (see e.g. Indeed 2015; Manpower Group Solution 2017). Companies should be aware that well-informed applicants are empowered applicants and that this potential can be used as a competitive advantage by actively providing information about career perspectives, the company and its vacancies (Manpower Group Solution 2017). The lack of this information and resulting inadequate responses may discourage the potential candidate from applying. Chatbots should be equipped with a broad range of information to be as relevant as possible for applicants.

An essential feature of the use of chatbots is the fact that the presence of a human contact person is replaced by a machine. In order to capture the effects in the survey, this paper draws on the theory of social presence. The theory of social presence (Short et al. 1976)describes the extent to which "an interlocutor is perceived as a natural person when communicating via electronic media" (Katzlinger 2007). Over the last few years, this theory has been attracting more and more attention (see e.g. Lee as in

\begin{tabular}{lllllll}
\hline 12 & Journal of E-Technology & Volume & 9 & Number & 4 & November 2018 \\
\hline
\end{tabular}


Rüggenberg 2007; Biocca et al. 2015)in research into human-computer interaction (HCI). Research by Gunawardena/Zittle, for example, has shown that social presence has a strong influence on the level of satisfaction during interaction (Gunawardena/ Zittel 1997). The research of Tu (2002) examines the perception of social presence in various forms of communication such as email, the bulletin board and real-time discussions in online learning environments.

$\mathrm{Tu}$ (2002) divides social presence into three dimensions: (1) social context, (2) online communication and (3) interactivity. Social context describes the user's perception of the communication environment. Online communication characterizes the use of language by the system. Interactivity describes all activities involving user participation such as response speed (Tu 2002; $\mathrm{Tu} /$ McIsaac 2002; Katzlinger 2007). Tu was able to demonstrate that a high degree of social presence has positive effects on the online interaction of the user (Tu 2002; Tu/McIsaac 2002). It is therefore important to attain such a high degree, as this leads to better interaction and more satisfaction. The degree of perceived social presence in turn influences the perception of the system (Gefen/Straub 2004). The degree of social presence can be significantly influenced by the various design options (see Blascovich et al. 2007; Baylor 2009; Etemad-Sajadi 2016; Liew et al. 2017). For example, social presence can be influenced by factors such as tonality. Lee and Nass note that systems that interact in an extroverted manner lead to a higher social presence than introverted, programmed systems (Lee/Nass 2003). According to Skalski/Tamborini, the factor of interactivity also increases the degree of social presence. Thus, a higher degree of interactivity also leads to an increase in the perceived social presence in the HCI (Skalski/Tamborini, 2007). Individual differences such as demographic, personal, social factors and previous experience can also influence the perception of social presence (Rüggenberg 2007; Blasovich 2002). The results give evidence that social presence might also be of great significance in the context of chatbots. For this reason, the constructs as defined by Tu (2002) are considered in the study.

\section{Approach and Results of the Empirical Study}

To evaluate the candidate perspective on recruiting chatbots, a quantitative empirical study in the form of an online survey was carried out. The survey was online 19 days in the period from 30 May to 17 June 2018. As this study is a work in progress, a convenience sampling method was chosen and the link to the questionnaire was distributed by email, social media and snowball sampling in a student environment (at the [blinded for review]). The survey included dichotomous "yes-no" questions, rating scales, semantic differentials, multiple and single answers that ensure a variation of the answer possibilities in order to prevent monotony (Raithel 2008). The questionnaire included an example of a recruiting chatbot describing the subject and the basic functioning. Pre-tests were carried out to verify the survey instrument before the actual launch of the survey. Thus, the preliminary questionnaire was examined" for its applicability, completeness, comprehensibility and quality" (Raithel 2008). The final online questionnaire consists of a minimum of 64 and a maximum of 67 question items (depending on filter questions) and three basic parts: (1) general questions on demographics, applicant behaviour and previous chatbot experience, (2) questions on usage determinants and design options for recruiting chatbots, (3) items based on the theory of social presence according to $\mathrm{Tu}(2002)$.

The online survey was accessed by a total of 451 participants with a completion rate of about 47 percent. This results in 213 participants in total. For the sake of simplicity, in the following, the answers" strongly agree" and "agree" are combined and interpreted as consent, while "disagree" and "strongly disagree" are interpreted as rejection. The graphs, however, show the differentiation of the individual response options. The following remarks are merely a descriptive evaluation of the research results ("work in progress"); statistical analyses will follow in the further course of the study.

The 213 participants can be divided into about 46 percent women and 54 percent men. The majority of respondents were 18 to 30 -year olds (61 percent), followed by 31 to 40 -year olds ( 17 percent), 41 to 50 -year olds ( 10 percent) and 51 to 60 -year olds ( 9 percent). With regard to professional status, results showed that predominantly employed persons (63 percent) and students (27 percent) took part in the survey. The remaining of the participants are trainees, pupils, pensioners, unemployed persons and persons employed in an area not listed in the survey.

With regard to the number of applications sent in the last five years, it can be seen that more than two thirds (72 percent) of respondents sent at least one application during this period. 47 percent sent one to ten applications, 17 percent between eleven and 30 applications and 8 percent even 31 or more applications within the defined time frame. Almost 40 percent of the respondents sent their last application less than one year ago.

Journal of E-Technology Volume 9 Number 4 November 2018 


\begin{tabular}{llcc}
\hline Demographics & & Absolute frequency (n) & Relative frequency (\%) \\
\hline Gender & Female & 98 & 46.01 \\
& Male & 114 & 53.52 \\
& Not specified & 1 & 0.47 \\
\hline Age & Under 18 & 2 & 0.94 \\
& 18 to 30 & 130 & 61.03 \\
& 31 to 40 & 36 & 16.90 \\
& 41 to 50 & 21 & 9.86 \\
& 51 to 60 & 19 & 8.92 \\
Professional status & 61 and older & 5 & 2.35 \\
& Pupil & 3 & 1.41 \\
& Trainee (m/f) & 4 & 1.88 \\
& Student & 57 & 26.76 \\
& Employed persons & 135 & 63.38 \\
& Unemployed & 2 & 0.94 \\
Pensioner & 1 & 0.47 \\
& Other & 11 & 5.16 \\
\hline
\end{tabular}

Table 1. Overview of demographic characteristics

\begin{tabular}{|l|l|c|c|}
\hline Applicant Behaviour & & Absolute frequency (n) & Relative frequency (\%) \\
\hline Number of applications & No applications & 60 & 28.17 \\
& 1 to 5 applications & 77 & 36.15 \\
6 to 10 applications & 24 & 11.27 \\
11 to 20 applications & 26 & 12.21 \\
& 21 to 30 applications & 10 & 4.69 \\
& 31 or more applications & 16 & 7.51 \\
& No applications & 5 & 2.35 \\
\hline Date of last application & 0 to 6 months ago & 48 & 22.54 \\
& 7 to 12 months ago & 35 & 16.43 \\
& 1 to 2 years ago & 31 & 14.55 \\
& 2 to 5 years ago & 38 & 17.84 \\
& Over 5 years ago & 56 & 26.29 \\
\hline
\end{tabular}

Table 2. Overview of interviewees' applicant behaviour

In the following, the respondents were asked about their attitude towards the application channels paper, e-mail, online form on the desktop pc, and mobile applications. The results shows that application via e-mail is the most popular with 80 percent positive and very positive ratings. Paper-based application are rated (very) positive by 62 percent followed by online forms via desktop computers by 48 percent. The least popular way to apply is the mobile device with only 23 percent of respondents rating such an

\begin{tabular}{llllll}
\hline 14 & Journal of E - Technology \\
\hline
\end{tabular}


option as positive or very positive. The channels used by the respondents for retrieving job and career related information are presented in Figure 1. Online job portals, personal networks and corporate career websites are among the most preferred channels for obtaining such information.

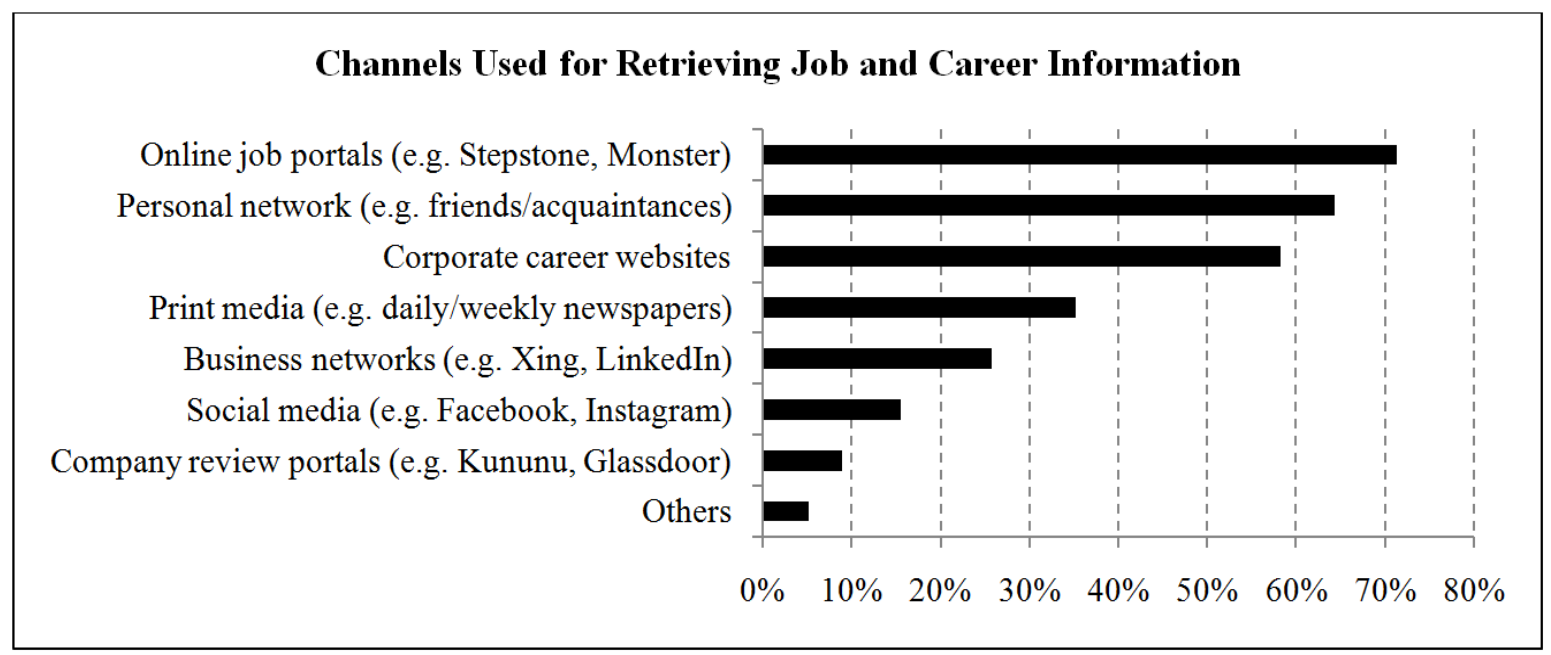

Figure 1. Channels for Retrieving Job and Career Information

A further important section of the questionnaire examined the participants' previous experience with chatbots. Of the 213 respondents, almost a quarter (24 percent) said they had already interacted with a chatbot. 6 out of 10 respondents rated their previous chatbot experience as at least positive. Looking at the context of the chatbot experience, 75 percent of those surveyed used them in the context of customer service, followed by the entertainment sector with 33 percent. Almost 6 percent of respondents have already interacted with a chatbot in the area of recruiting.

Looking at the advantages or motivators of chatbot usage in Figure 2, it becomes clear that all the factors included in the questionnaire rewarded mostly approval (more than 50 percent strongly agreed or agreed) as advantages of chatbots. However, differences in the degree of agreement are evident. The biggest motivation drivers are thus the speed of responses and reactions (92 percent), accessibility at any time ( 92 percent) and accessibility at any location ( 87 percent). In comparison, the low inhibition threshold for asking questions is the smallest motivator with 56.34 percent agreement.

\section{Using a recruiting chatbot has advantages due to...}

Accessibility (regardless of locations)

Fast responses and reactions Accessibility (around the clock)

Simlicity of use

Unprejudiced and non-discrimatory interaction

Low inhibition threshold when asking questions

Comprehensability of answers

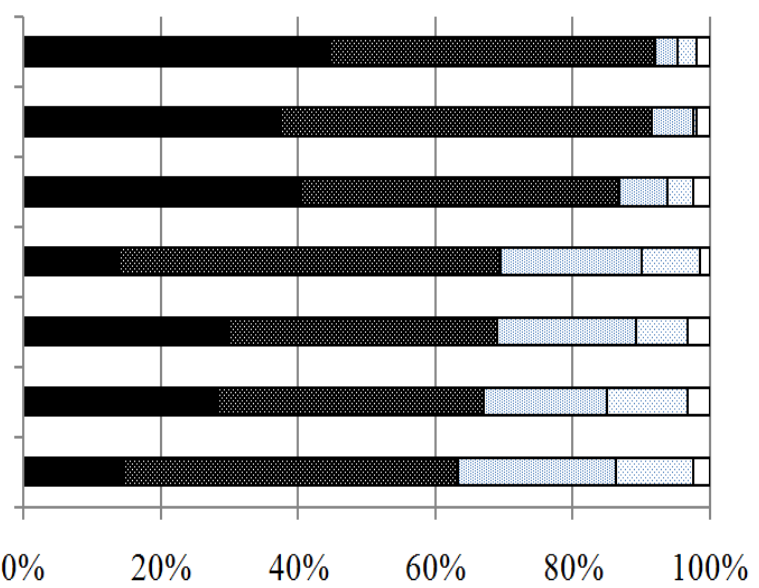

- Strongly agree

图Agree $\square$ Neither agree nor disagree

口Disagree

口Strongly disagree

Figure 2. Motivators of Recruiting Chatbot Usage 
The respondents' assessment of barriers to recruiting chatbot usage are presented in Figure 3. The lack of understanding of complex contexts, the high susceptibility to errors and the low level of competence towards people are perceived as major barriers to use. At least two thirds of the respondents consider these three items to be an obstacle. The results regarding data protection concerns are not so clear. Approximately 40 percent of respondents have data protection concerns, while 30 percent see no problems with regard to the handling of personal data. This result surprises somewhat given the importance of this topic in Germany. Perhaps this is due to the novelty of the topic and also the strong spread and everyday use of traditional (person-toperson) messaging services.

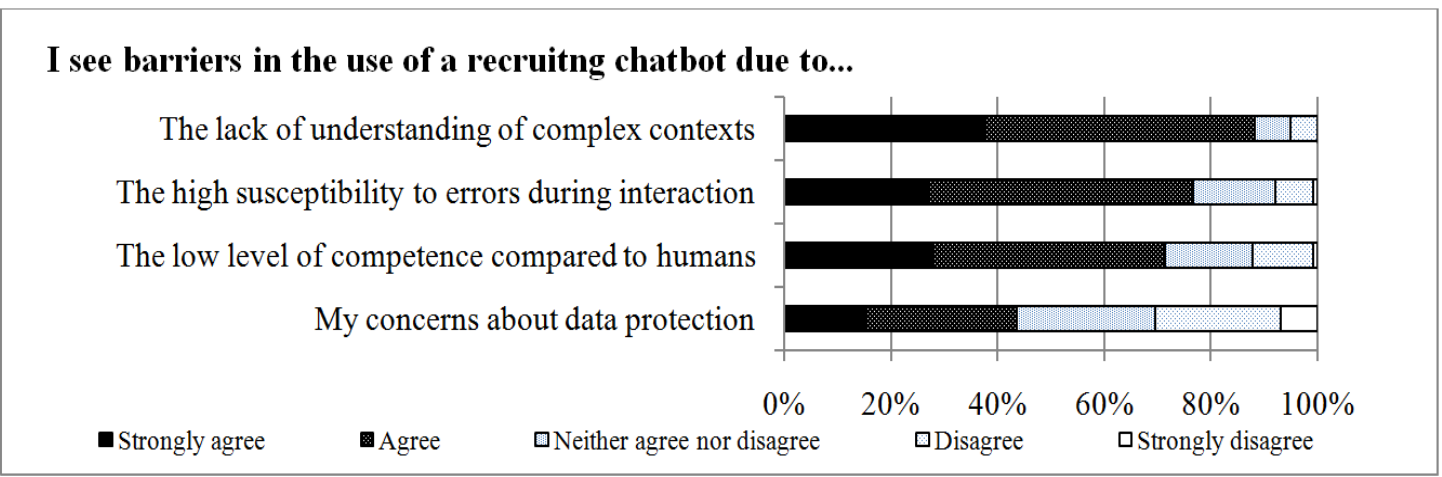

Figure 3. Barriers of Recruiting Chatbot Usage

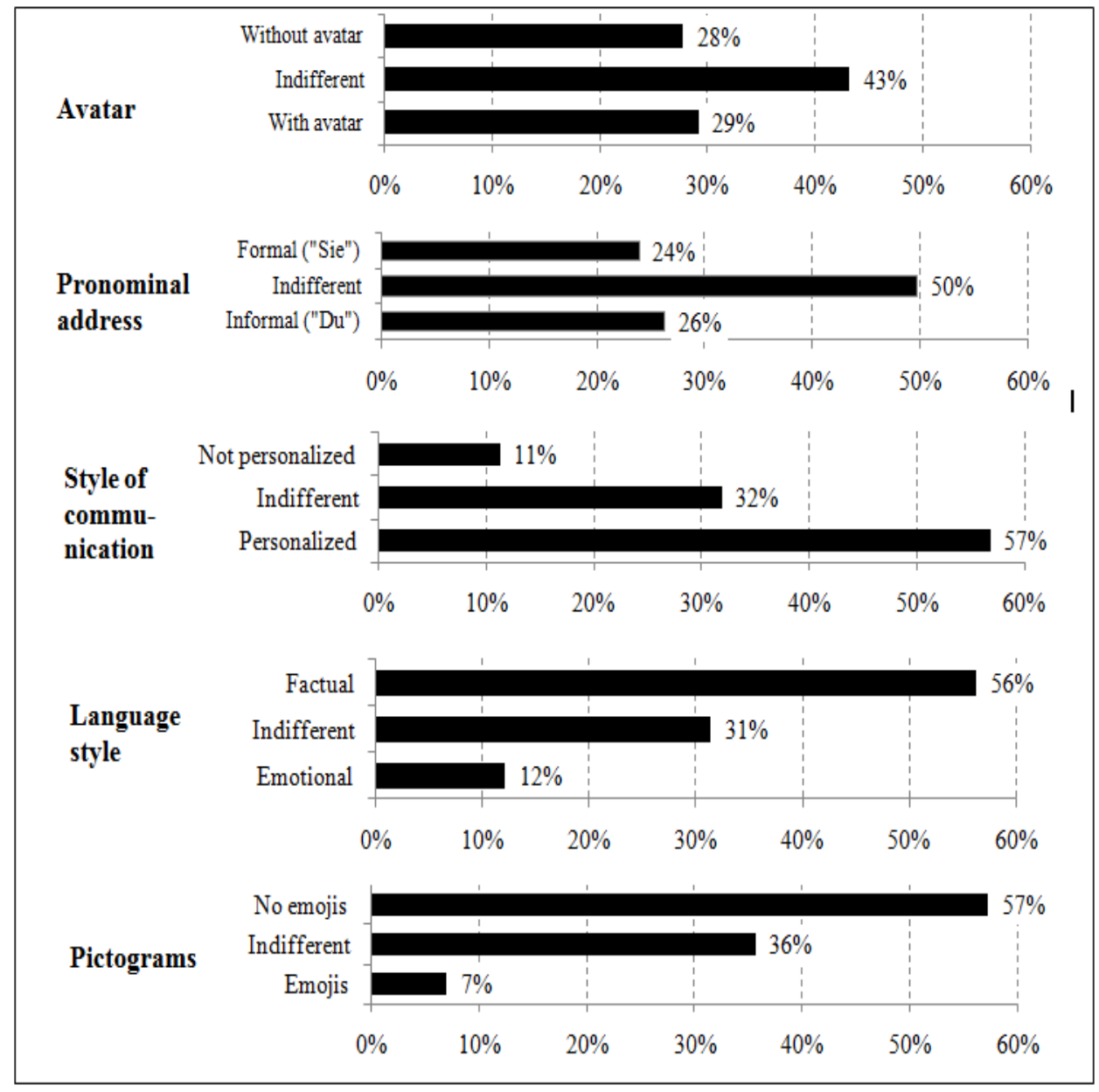

Figure 4. Design Preferences on External Appearance and Tonality 
With regard to design preferences as presented in Figure 4, there are not always clear tendencies on the subjects of external design and tonality. For example, 29 percent would like the chatbot to appear in the form of an avatar, while 28 percent do not. The largest share, 43 percent, are undecided. The same can be said about the decision concerning a particularity of the German language with respect to the formal or informal address. About 26 percent of respondents prefer the informal "Du", whereas 24 percent prefer the formal form of being addressed by "Sie". However, for the majority, it does not matter one way or another. For the remaining design aspects surveyed, clearer results can be seen. For example, 57 percent would like a personalized style of communication, while only 11 percent do not. In terms of language style or tonality, around 56 percent prefer factual language and only 12 percent an emotional language. The clearest result is related to the question of the use of emojis during chatbot interaction. Almost 60 percent are against the use of emojis, whereas only 7 percent are in favour.

With regard to the preferences of the functions, as shown in Figure 5, more than 90 percent would like to use the recruiting chatbot to answer simple questions and about 85 percent to get quick help. For each of these two items, less than 6 percent disagree. A majority of 62 percent also agree with the use of the chatbots in order to get advice on vacancies. Applying via the chatbot and conducting the job interview with it was rejected by the majority of respondents.

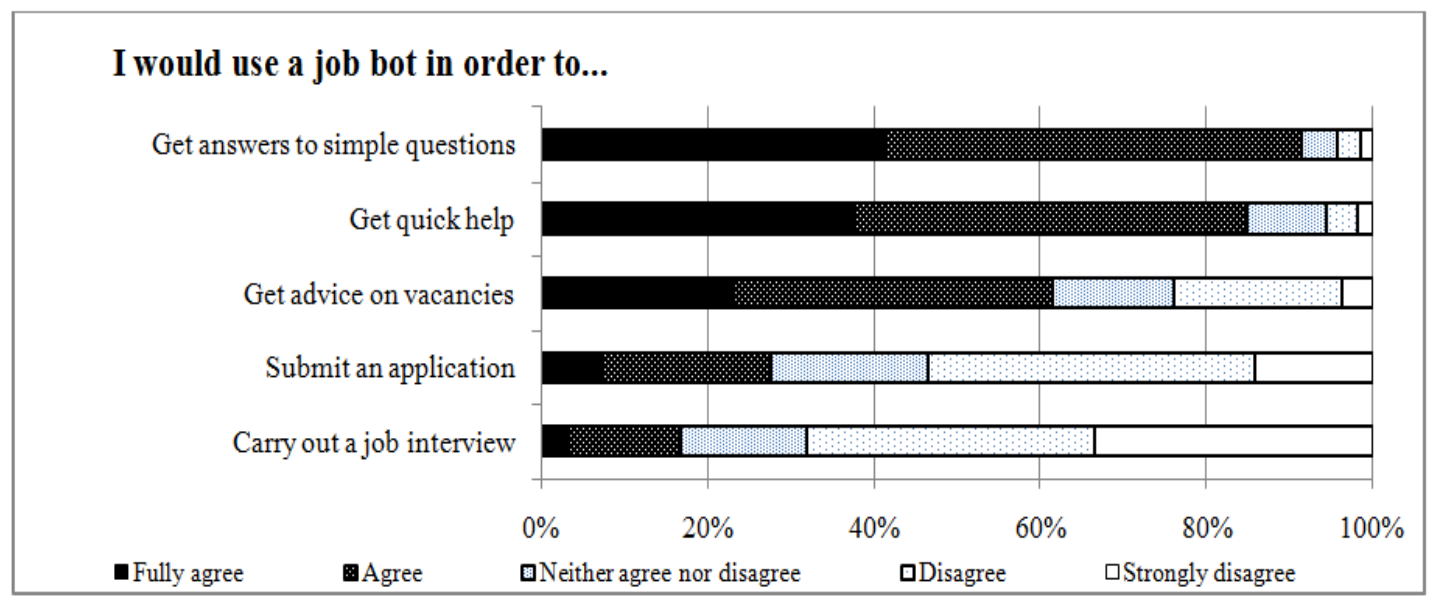

Figure 5. Respondents' Preferences on Chatbot Functions

\section{I would like to receive information from a job bot about ...}

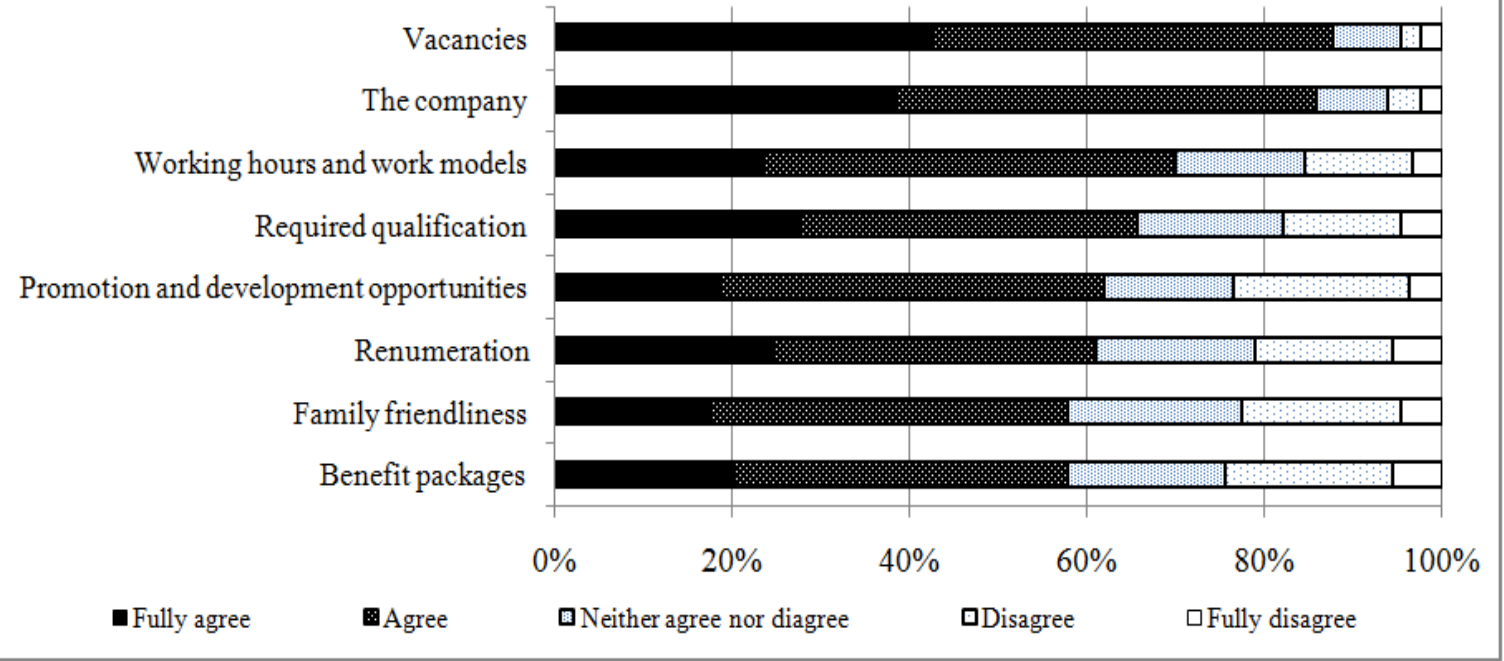

Figure 6. Respondents' Preferences on Chatbot Content 
Looking at the question on content, it can be seen that more than half of the respondents see the chatbot as a useful information system for all types of content options surveyed. However, the survey identified some content types that should be prioritized. The by far most important contents are vacancies ( 88 percent) and career related information on the company ( 86 percent). These categories are followed by working hours and work models (70 percent), required qualifications ( 66 percent), promotion and development opportunities (62 percent) and remuneration (61 percent). Family friendliness and benefits are rated as being least important at 58 percent.

The interviewees' response to the question on the future willingness to use job bots reveal that this is generally given. Figure 4.7 shows, for example, that the majority of respondents answered the question in the affirmative with almost 70 percent. Only a small proportion of 17 percent disagree.

In the last part of the survey, the constructs of social presence have been subject to analysis. Beginning with the evaluation of the dimension "social context" as shown in Figure 7, it was found that the majority of respondents felt that communication with a recruiting chatbot is impersonal (73 percent) but an informal and casual (62 percent) form of communication. The statement "I feel comfortable communicating with a job bot" shows that a majority of the respondents, 54 percent, were undecided. A third say they do not feel comfortable communicating with a bot. In addition, the majority of respondents do not consider communication with a job bot to be a social or empathic form of communication.

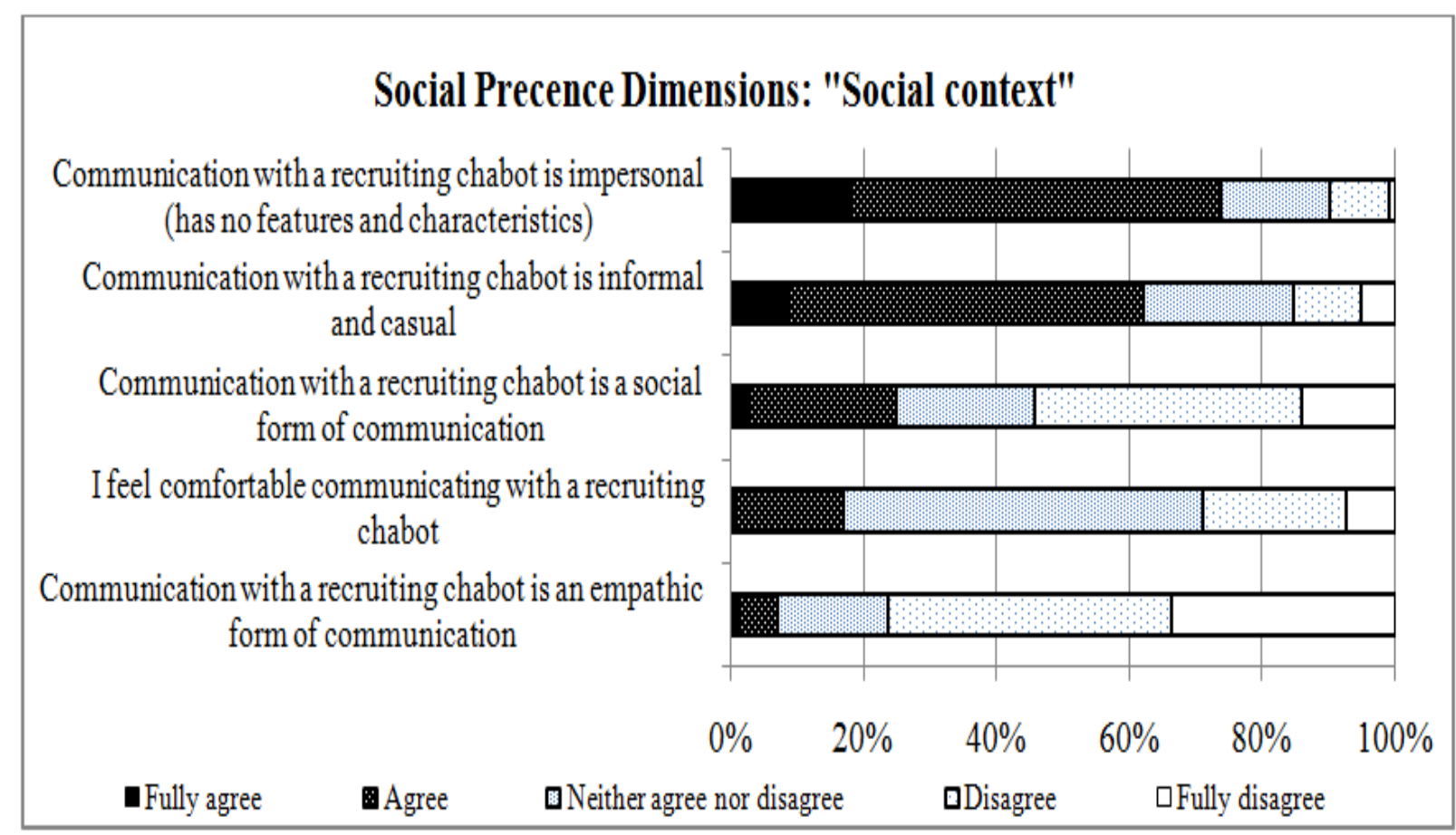

Figure 7. Results on the Social Presence Dimension "Social Context"

Concerning the construct of online communication, the greatest degree of agreement is with the statements that the language a chatbot uses can be easy to understand ( 86 percent) and meaningful (66 percent), which underlines the positive aspects of this form of communication. However, 57 percent of respondents agree that it is difficult to express what they want to say when communicating with a recruiting chatbot, and almost half are of the opinion that communication is not trustworthy enough to reveal personal and sensitive information. The lowest degree of agreement can be found in response to the statements that communication can be motivating and convey feelings and emotions.

The third construct examined is the dimension of interactivity. It turns out that the statements "The job bot responds immediately" and "job bots usually respond to my messages" are agreed with by a majority with 81 percent and 66 percent, respectively, while less than 3 percent disagree. Somewhat less than a third of respondents feel comfortable communicating with a recruiting

\begin{tabular}{lllllll}
\hline 18 & Journal of E - Technology & Volume & 9 & Number & 4 & November \\
\hline
\end{tabular}




\section{Social Precence Dimensions: "Online Communication"}

The language that a recruiting chatbot uses can be easy to understand

The language used by a recruiting chatbot can be meaningful

It is difficult to express what I want to say when communicating with a recruiting chatbot

The communication with a recruiting chatbot is not trustworthy enough to reveal personal data

The language used by are cruiting chatbot can be motivating

Feelings and emotions can be conveyed through communication with a recruiting chatbot

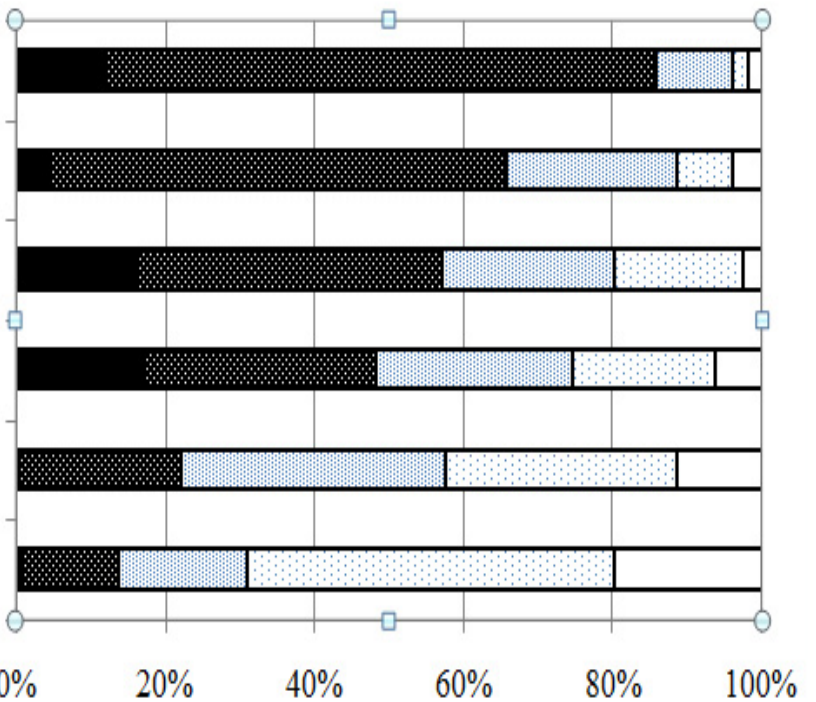

-Fully agree $\quad$ Agree $\quad$ Neither agree nor disagree $\quad$ Disagree $\quad \square$ Fully disagree

Figure 8. Results on the Social Presence Dimension"Online Communication"

\section{Social Precence Dimensions: "Interactivity"}

The job bot responds immediately

Job bots usually respond to my messages

Communication with a job bot is pleasant

I would feel comfortable asking the job bot general questions about jobs and the company

I would feel comfortable applying for a job through a job bot

I would feel comfortable if the job bot made a pre-selection of the applicants

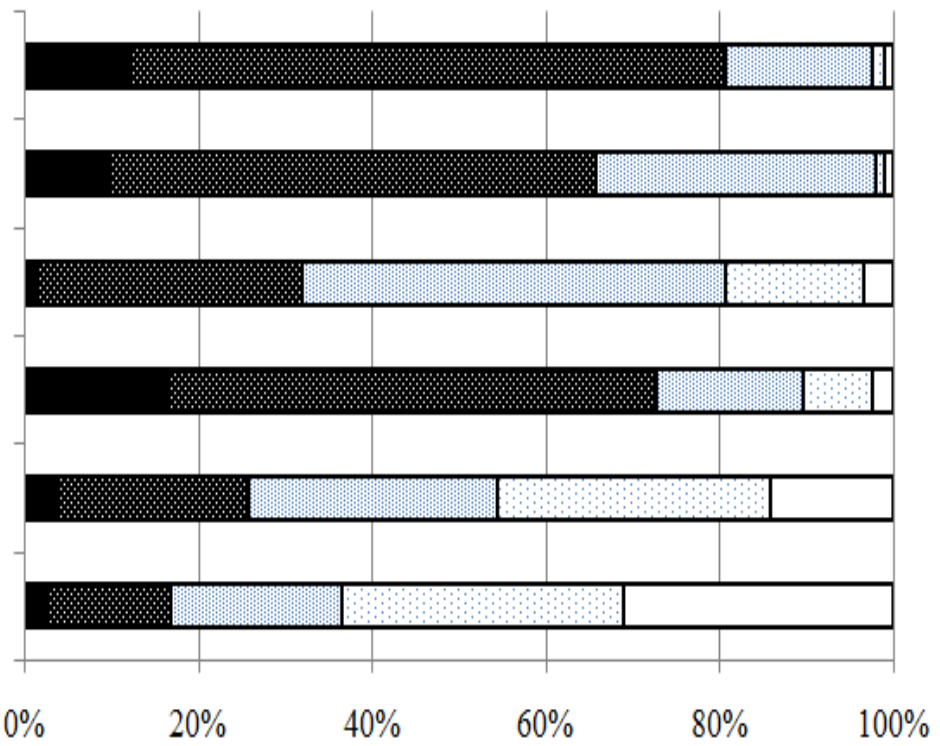

- Fully agree $\quad$ Agree $\quad$ DNeither agree nor disagree $\quad \square$ Disagree

Figure 9. Results on the Social Presence Dimension"Online Communication" 
chatbot. The majority, 49 percent, selected the option "neither agree nor disagree". With regard to the degree to which respondents feel comfortable during the various forms of interaction, further tendencies can be observed. More than 70 percent would feel comfortable asking the recruiting chatbot questions. A quarter of the respondents would also feel comfortable applying via the bot. The biggest disagreement (63 percent), with the lowest agreement level (17 percent), is with the statement that respondents would feel comfortable if the chatbot made a preselection of the applicants.

\section{Implications and Limitations of the Study}

\subsection{Managerial Implications}

First of all, it can be stated that the fundamental willingness to use job bots, as revealed in the evaluation, represents a good basis for the use of chatbots in the area of recruiting. On the basis of the usage barriers investigated, the first recommendation is that recruiting chatbots should not be put into operation hastily. High susceptibility to errors, lack of understanding of recruiting chatbots and a lower level of competence when compared to humans are usage barriers already. These can only be overcome by implementing effective and well-engineered chatbot solutions. For this reason, the development and implementation of the chatbots should be well thought through and subjected to several test runs before being launched. Concerns about data protection are, according to the evaluation, the smallest perceived barrier. However, it should always be clear to the applicant which data is stored and for what purpose not to jeopardize the present unconcernedness and the apparent trust in such solutions.

For the implementation of recruiting functions, it is recommended to use the bot initially for the tasks of quick help, to answer simple questions and to offer advice on vacancies, since the majority of respondents are willing to use bots for these purposes. Less popular is the function to submit applications via the bot. Here, one could consider implementing the function in the dialog system anyway and to offer an additional link to the classical online application form or the e-mail address for the application via e-mail. The applicant then has alternatives to choose from and the first candidates can be introduced to this function. Since the willingness to conduct a job interview with the bot is very low, it is recommended not to implement this function for the time being. If, however, the job bot proves to be a good tool for carrying out the above-mentioned functions and is frequently used, this can be the next step in the further development towards a recruiting assistant.

With regard to the recruiting chatbot content desired by the applicants, care should be taken to ensure that the chatbot contains information on all the subject areas asked about. Particular attention must be paid to information on job vacancies, the company in general, which candidates consider to be very important. Even if the evaluation reveals only slight tendencies towards agreement, studies of social presence such as Etemad-Sojadi and Liew et al show that avatars have a positive influence on the perception of a system (Etemad-Sajadi 2016; Liew et al. 2017). Due to the clear preference for factual language, this should be carried out accordingly. In addition, the bot should not use emojis, as this was rejected by the majority of respondents in the survey.

\subsection{Limitations of the Study}

The study at hand is a work in progress and based on a convenient sample. The results can therefore only be generalised to a limited extent and are not representative. Another limitation is based on the use of closed questions. Respondents did not have the opportunity to mention factors that not have been considered in the questionnaire. This creates the risk that essential motivation drivers or barriers are not identified. In addition, the descriptive evaluation at hand is not sufficient. Future studies have to apply explorative and confirmative statistics to gain more insights into the underlying dependencies and interrelationships of chatbot design decisions and chatbot acceptance as well as usage. The limitations outlined above illustrate the need for further research. Another shortcoming of this study is that design aspects of chatbots were surveyed at a descriptive and abstracting level. Concrete design recommendations could therefore not be drawn up in this study. In subsequent research, for example, there is a need to deal with the design of chatbot features and content, since there are no indications as to its specific design and the associated effect. For this purpose, for example, the method used could be an experiment in conjunction with a quantitative questionnaire (see Liew et al. 2017).

\section{References}

[1] Asher, N. (2017). A warmer Welcome. Application of a Chatbot as a Facilitator for New Hires On boarding. Master Thesis. Linnaeus University, Kalmar. 
[2] Baylor, A. L. (2009). Promoting motivation with virtual agents and avatars. role of visual presence and appearance. Retrieved from http://rstb.royalsocietypublishing.org/content/364/1535/3559.short on 15.07.2018.

[3] Biocca, F., Lombar, M., Freeman, J., IJsselsteijn, W., Schaevitz, R. J. (2015).Immersed in Media. Telepresence Theory, Measurement, \& Technology. Springer International Publishing Switzerland.

[4] Blascovich, J. (2002). Social Influence within Immersive Virtual Environments. The Social Life of Avatars. London: SpringerVerlag.

[5] Bollessen, D. (2016). The progressive shortage of skilled workers due to demographic change. Thinkable concepts and success strategies for long-term employee retention: Diplomica publishing house GmbH.

[6] CHRIS (2017). Themenspecial 2017. Active Sourcing and Social Recruiting. Ausgewählte Ergebnisse der Recruiting Trends 2017. Study of Otto-Friedrich-Universit ät Bamberg as commissioned by Monster Worldwide Deutschland GmbH. Published by Poolia. Retrieved from https://www.poolia.de/Files-de/Gehaltsreport\%202017/Poolia_Recruiting_Trends_2017_All.pdf on 29.07.2018.

[7] CHRIS (2018). Themenspecial 2018. Social Recruiting und Active Sourcing. Ausgewählte Ergebnisse der Recruiting Trends 2018. Study of Otto-Friedrich-Universität Bamberg as commissioned by Monster Worldwide Deutschland GmbH. Retrieved from https://www.uni-bamberg.de/fileadmin/uni/fakultaeten/wiai_lehrstuehle/isdl/Studien_2018_1_Active_Sourcing_DigitalVersion_20180207_ff_A.pdfon 29.07.2018.

[8] Desaulniers, S. (2016). Chatbots rise, and the future may be ,re-written'. Retrieved from https://www.cnbc.com/2016/04/08/ chatbots-rise-and-the-future-may-be-re-written.html on 19.11.2018.

[9] Grieger \& Cie. Marktforschung (2016). Data protection is important to over 83 percent of Germans. Retrieved from https:// www.splendid-research.com/de/statistiken/item/datenschutz-fuer-mehrheit-wichtig.html on 20.07.2018.

[10] Eisenkrämer, S. (2017). How artificial intelligence can help in recruiting. Published by Springer Professional. Wiesbaden. Retrieved from https://www.springerprofessional.de/recruiting/kuenstliche-intelligenz/wie-kuenstliche-intelligenz-im-recruitinghelfen-kann/15292586 on 17.06.2018.

[11] Etemad-Sajadi, R. (2016). The impact of online real-time interactivity on patronage intention: The use of avatars. Computers in Human Behavior, 61, 227-232.

[12] Ferdinand, J., Jetzke, T. (2017). Voice Computing. ubiquitous speech recognition. In: TAB (15).

[13] Gefen, D., Straub, D. W. (2004). Consumer trust in B2C e-Commerce and the importance of social presence. Experiments in eProducts and e-Services. Omega, 32 (6) 407-424.

[14] Gennermann, H., Hack, S. (2011). Quality standards for chatbots in library information in Germany. Cologne University of Applied Sciences.

[15] Hensel, M. / Litzel, N. (2018). A look into the future of chatbots. Retrieved from https://www.bigdata-insider.de/ein-blick-indie-zukunft-der-chatbots-a-678009/ on 20.07.2018.

[16] Indeed (2015). Study on talent recruitment. What's important to today's applicants. Retrieved from https://docplayer.org/ 4062639-Indeed-studie-zum-mobile-recruitment-in-deutschland-2015.html on 19.11.2018.

[17] JobStairs (2016). Whitepaper. Applicant 4.0 - a status quo from the applicant's point of view. Retrieved from https:// www.jobstairs.de/information/umfrage-bewerbung-4.0.pdf on 19.11.2018.

[18] JobStairs (2017). Whitepaper. Recruiter 4.0. Retrieved from http://www.mynewsdesk.com/de/documents/whitepaper-recruiter4-punkt-0-67570 on 19.07.2018.

[19] Jung, J., Niemeyer, S. (2017). Artificial intelligence in tourism. Your guide to how to inspire with chatbots. Bremen: neustaeTourismus GmbH.

[20] Katzlinger, E. (2007). The relationship between social presence and privacy in learning platforms. In: Reinventing Studying Rethinking Higher Education, 191-201.

[21] Kramer, B. (2018). Robot Recruiting. The algorithm does not discriminate. Retrieved from https://www.zeit.de/arbeit/2018-01/ roboter-recruiting-bewerbungsgespraech-computer-tim-weitzel-wirtschaftsinformatiker/komplettansicht on 20.05.2018.

[22] Krenz, N. (2017): Project: Own chatbot - why, why, why? Hg. v. Social Media Knigge. Retrieved from https://www.social- 
media-knigge.de/2017/05/09/projekt-eigener-chatbot-wieso-weshalb-warum/ on 18.07.2018.

[23] Kreuzmann, L. (2018). Interview with a bot. Retrieved from http://www.zeit.de/2018/04/chatbot-vorstellungsgespraechjobvermittlung-personalarbeit on 11.07.2018.

[24] Lee, K. M., Nass, C. (2003). Designing Social Presence of Social Actors in Human Computer Interaction. Lauterdale, Florida. In: Human Computer Interaction, 289-296.

[25] Liew, T. W., Tan, S., Ismail, H. (2017). Exploring the effects of a non-interactive talking avatar on social presence, credibility, trust, and patronage intention in an e-commerce website. Human-centric Computing and Information Sciences, 7(42).

[26] Lüpke-Narberhaus, F. (2014). First Name Discrimination. Nobody wants an Ali on the team. Retrieved from http:// www.spiegel.de/lebenundlernen/schule/auslaendische-vornamen-migranten-diskriminierung-durch-firmen-bestaetigt-a960855.html on 14.06.2018.

[27] Manhart, K. (2018). FAQ Machine Learning. What you need to know about machine learning. Retrieved from https:// www.computerwoche.de/a/was-sie-ueber-maschinelles-lernen-wissen-muessen,3329560 on 19.05.2018.

[28] ManpowerGroup Solutions (2017). What applicants really want. Change of power in the application process. Retrieved from https://www.manpowergroupsolutions.de/fileadmin/manpowergroupsolutions.de/Download/ MGS_Well_Informed_Candidate_D_20170426.pdf on 01.08.2018.

[29] Market agent (2015). 360 degree study. Employer Branding. Retrieved from http://www.marketagent.com/webfiles/ MarketagentCustomer/pdf/9336cf5e-3f55-40cc-996c-24f60d57defd.pdf on 13.07.2018.

[30] Marr, B. (2018). How Artificial Intelligence Is Making Chatbots Better For Businesses. Retrieved from https://www.forbes.com/ sites/bernardmarr/2018/05/18/how-artificial-intelligence-is-making-chatbots-better-for-businesses/ on 29.11.2018.

[31] Quarteroni, S.,Manandhar, S. (2007). A chatbot-based interactive question answering system. In: Proceedings of the $11^{\text {th }}$ Workshop on the Semantics and Pragmatics of Dialogue, Trento (Italy), May 30 - June 01 2007, 83-90.

[32] Queb (2017). Bots in recruiting. Opportunities, possibilities, digital change. Retrieved from https://www.queb.org/bots-imrecruiting/ on 20.06.2018.

[33] Raithel, J. (2008). Quantitative Research. A practical course. $2^{\text {nd }}$ Aufl. Wiesbaden: VS Publishing House for Social Sciences.

[34] Knight, A. (2010). E-Recruiting. A modern form of recruitment. Munich: Thomas Martin.

[35] Rüggenberg, S. (2007). So near and yet so far. Social presence and trust in computer mediated communication. University of Cologne, Cologne. Psychological Institute.

[36] Schlicht, M. (2016). The Complete Beginner's Guide to Chatbots. Everything you need to know. Retrieved from https:// chatbotsmagazine.com/the-complete-beginner-s-guide-to-chatbots-8280b7b906ca on 11.06.2018.

[37] Schönecker, H. G. (1982). Communication technology and operator acceptance. In: Research Project Office Communication 1st Munich: CW-Publ.

[38] Shawar, A. B., Atwell, E. (2007) Chatbots: Are they Really Useful? LDT-Forum 2007, 22 (1) 29-49.

[39] Short, J., Williams, E., Christie, B. (1976). The Social Psychology of Telecommunications. London: Wiley.

[40] Slaghuis, B. (2016). Kununu study: Applicants want more transparency and speed. Retrieved from https://www.berndslaghuis.de/karriere-blog/kununu-studie-bewerber-bewertungen/ on 19.07.2018.

[41] Skalski, P., Tamborini, R. (2007). The Role of Social Presence in Interactive Agent-Based Persuasion. Media Psychology 10 (3) 385-413.

[42] Stucki, T.; D’Onofrio, S.; Portmann, E. (2018): Chatbot - The digital helper in the company. Practical examples from Swiss Post. HMD Practice of Business Informatics, 55 (4) 725-747.

[43] Sun, L. (2017). Facebook Inc's Chatbots Hit a 70\% Failure Rate. Were the social network's chatbot ambitions ahead of their time? Retrieved from https://www.fool.com/investing/2017/02/28/facebook-incs-chatbots-hit-a-70-failure-rate.aspx on 9.07.2018.

[44] Tu, C. (2002). The Measurement of Social Presence in an Online Learning Environment. In: International Journal of ELearning, 1 (2) 34-45.

[45] Tu, C., McIsaac, M. (2002). The Relationship of Social Presence and Interaction in Online Classes. The American Journal 
of Distance Education, 16 (3) 131-150.

[46] Van Euwen, M. (2017). Mobile conversational commerce. Messenger chatbots as the next interface between businesses and consumers. Master Thesis. University of Twente, Enschede.

[47] Zadrozny, W., Budzukowska, M., Chai, J., Kambhatla, N., Nicolov, N. (2000). Natural Language Dialogue for Personalized Interaction. Communications of the ACM (8). 